\title{
'PAÑA, PALOMO Y GATO...': \\ LA LEYENDA DEL PAÑAMÁN EN LOS PAÑAMANES DE FANNY BUITRAGO, UN ESLABÓN DEL META-ARCHIPIÉLAGO CARIBEÑO
}

\author{
POR \\ Ligia S. Aldana \\ SUNY, New Paltz
}

Como proyecto de re-escritura del Caribe, La isla que se repite: El Caribe y la perspectiva posmoderna ${ }^{1}$ de Antonio Benítez Rojo se propone reconstituir la memoria y el Ser caribeño en una realidad sin interrupciones al reincorporar el eslabón que encadena el Caribe colombiano con el resto del ámbito insular. El importante capítulo 6 de la Parte III del texto, titulado "El libro"" reconecta una pieza crucial de lo que Benítez Rojo llama "el rompecabezas del Caribe" (221), para así "encajar algunas islas, ciertas ciudades y puertos, tramos costeros, penínsulas y golfos cuya ausencia configura huecos de bordes irregulares en la superficie azul turquesa del Caribe" (221). Uno de estos huecos contiene el archipiélago de San Andrés, territorio colombiano de ultramar, cuya inclusión en el continuo caribeño forma el puente al área continental colombiana y suramericana. La extensa novela de la escritora colombiana y barranquillera Fanny Buitrago, Los pañamanes, lanzada al mercado en 1979, le brinda a Benítez Rojo el material necesario para establecer la conexión caribeña y enfatizar, irónicamente a través de la escritura y del libro, una premisa esencial de La isla: el significativo rol del mito y de la oralidad en el Caribe y el Ser caribeño.

Lo anterior no es lo novedoso de La isla, en realidad. Lo sublime es el acto mismo de Benítez Rojo de legitimar la inscripción del archipiélago de San Andrés y Providencia en la novela de Buitrago, un meta-archipiélago por excelencia evocado en el espacio de la novela bajo el nombre de San Gregorio y Fortuna. Esa "rara pieza del rompecabezas caribeño" (221) es también el espacio del otro colombiano, la cara caribeña del "color del tabaco quemado" que lucha por ser reconocida aún ahora dentro de los nuevos parámetros plurinacionales.

1 Todas las citas de este estudio provienen de la 2da. edición de La isla publicada por Ediciones del Norte en 1996.

2 Antonio Benítez Rojo recupera la novela de Buitrago en su artículo, "Los pañamanes: Mito y realidad en el Caribe" de 1982. La revisada, editada y ampliada versión de dicho artículo se convierte en el capítulo 6 de La isla. 
El mito, como elemento orgánico de Los pañamanes brinda el material de una pieza esencial tanto del Ser caribeño como del Ser colombiano. Es importante por ende, además de reconocer la agenda de Benítez Rojo en su análisis de Los pañamanes, explorar la forma en que la novela misma re-escribe el mito que organiza el texto, la leyenda del pañamán, como muestra del carácter mutante de lo caribeño, característica que Benítez Rojo enfatiza y que el texto de Buitrago performs al inscribir la leyenda como mito fundacional de la isla. Al mismo tiempo la leyenda se convierte en otra cosa en la novela, destinada a seguir cambiando y resignificando, como lo hace al definir lo colombiano caribeño.

Los pañamanes es ciertamente una novela "rara" por la peculiaridad del espacio en que se desarrolla y su tratamiento de la realidad caribeña. ${ }^{3}$ La novela es un texto rizomático que extiende sus raíces desde diversos polos narrativos contenidos dentro del simbólico archipiélago de San Gregorio y Fortuna. Dicho archipiélago del Mar Caribe sirve de puente entre el ámbito insular y tierra firme colombiana. Benítez Rojo examina la línea de los grupos socioculturales originarios que participaron en la invasión y colonización de la isla: ingleses, españoles y colombianos, al igual que los franceses. En La isla, Benítez Rojo examina las tres generaciones representativas de las líneas socioculturales anteriores (228-31). El mito inaugural de la isla, la leyenda del pañamán, se ve repetido y re-interpretado en cada una de tales generaciones para, finalmente, verse libres “del tabú de la piel” (231), y así, de acuerdo con Benítez Rojo, "la piel pierda su antigua memoria y borre las cicatrices de latigazos y hierros al rojo, de los cepos y grilletes de la plantación; o bien, lave sus propias manchas de culpa, la culpa de las factorías de negros, del terrible middle passage, de la compra-venta de la carne, del mayoral y el barracón" (231).

La interpretación que Benítez Rojo ofrece de la evolución del mito tal y como es vivido y experimentado por las tres generaciones que habitan San Gregorio reconoce el deseo profundo del texto de poder finalmente trascender el trauma de la trata esclavista.

\footnotetext{
El momento de la publicación de Los pañamanes es igualmente significativo, ya que Buitrago se enfrenta directamente a una realidad literaria colombiana abrumada por el legado de Cien años de soledad. En efecto, la casa editorial denota su conciencia de dicha realidad al imprimir en la portada de un número de ejemplares de la primera edición una inscripción que hace alusión directa a lo anterior. Las líneas leen inmediatamente debajo del título: "Una de las novelas más genuinas de la literatura hispanoamericana contemporánea, que recuerda al Gabriel García Márquez de los primeros tiempos". Estas palabras intentan insertar la novela de Buitrago dentro de la tradición literaria dominante para adherirla a un mercado ya condicionado por lo garcíamarquiano. Además, la indicación sobre la producción "temprana" de García Márquez apunta a la calidad "genuina" tanto de la novela de Buitrago como los primeros pinos literarios de García Márquez. Es evidente que, en la era de los setenta y comienzos de los ochenta, la única referencia existente para definir y catalogar un texto literario era a través de la narrativa de García Márquez. Esta dimensión de la novela de Buitrago fue examinada en mi tesis de doctorado Violencia, raza, mito e historia en la literatura del Caribe colombiano.
} 
Dentro de otra dimensión del texto de Buitrago, este deseo es subvertido para afirmar la imposibilidad de hacerlo realidad.

En esa otra historia, levemente subrayada en el análisis de Benítez Rojo sobre la novela de Buitrago, la idea es contribuir a mantener viva la memoria de la esclavitud y resistir el final del tabú de la piel. "La tinieblamenta", la barra de amigos de la tercera generación isleña y sus avatares, conforman un foco primordial en la trama de la novela. Denominados "tinieblos" por su color de piel oscura, los nueve personajes centrales, "la patota de tinieblos", ejemplifica la mezcla étnica y la poliglosia que caracteriza la isla. Todos, Goyo Saldaña, Nick Boy, Terranova González, Pinky Robinson, Epaminondas Jay Long, Pepe el Tranquilo, Bello Román y Nicasio Beltrán -a excepción de Lord Caca- provienen de líneas familiares que Buitrago traza hasta los clanes fundadores de la isla, directa o indirectamente. O sea dentro de líneas patrilineales legítimas o ilegítimas. De una u otra forma, los tinieblos pertenecen o se mueven dentro del espacio de El Arenal. Este aparente sub-espacio de la novela, un barrio pobre, marginal y objeto de deseo de los negociantes y políticos de la isla, contiene el grupo y las actividades que le prestan a San Gregorio su carácter caribeño, ecléctico y culturalmente heterogéneo. Benítez Rojo denomina este tipo de espacio una ciudad "fetal", "una célula social" (233). De acuerdo a las escasas oportunidades para sobrevivir que existen allí, los tinieblos son ladrones y pescadores, hombres de negocio y borrachos empedernidos, cuyas vidas fluctúan entre la legalidad y la marginalidad. Las andanzas de los tinieblos, sus rumbas, viajes de pesca, empresas de negocios, amores, éxitos y fracasos mueven la narrativa y se ramifican en sucesos que tienen que ver con interacciones a un nivel más amplio en la novela.

El archivo personal de Goyo Saldaña, personaje principal de la novela, compuesto de múltiples fuentes, es el archivo maestro del texto. Cada uno de los dieciséis capítulos de la novela está enmarcado por un documento diferente proveniente de dicho archivo, fragmentos del cual están estratégicamente posicionados al principio y al final del capítulo. Benítez Rojo apunta a la calidad de Los pañamanes como novela-mito (231), "pero no mito épico, sino mito del desarraigado que sueña con reunir los pedazos de su dispersa identidad más allá de las barreras de la Plantación” (231). Según Benítez Rojo, la novela ejecuta "un performance doble" (232) que desea mitificar y trascender lo simbólico simultáneamente (232). Por tanto, el interés de Benítez Rojo en La isla radica en el testimonio oral que emana de la vida de los habitantes de El Arenal y de la isla para localizar lo marginal y proyectarlo como elemento cambiante, enraizado dentro de una dimensión oral.

En el texto de Buitrago lo oral proviene de dos elementos deterministas que gobiernan la vida de cada uno de los personajes y del espacio: la leyenda del pañamán. 
Dicha leyenda, foco de este análisis, organiza la dinámica de todas las relaciones que se dan en la isla, las cuales están ejemplificadas en el diverso grupo de los tinieblos. ${ }^{4}$

La leyenda del pañamán está narrada en el primer capítulo de la novela, elemento que marca su visible relevancia. Partiendo de esta premisa, es crucial examinar el contenido de la leyenda para identificar los mecanismos que la componen y su significado. Me propongo así seguir con más detalle la línea trazada por Benítez Rojo en La isla para develar las tradiciones que convergen en la constitución de esta leyenda explicativa y normativa, un instrumento más en el proceso de conectar a Colombia con el resto del Caribe.

\section{La leyenda del pañamán relata la emergencia}

de un náufrago español -The Spanish Man- [que] surgió de la vecina isla de Fortuna, imponiéndose con su regia apostura a los descendientes de una próspera colonia puritana cuyos espíritus tradicionales continuaban ejerciendo discriminación entre negros y blancos, repartidos en poblaciones separadas, aunque la mayoría poseyera el color del tabaco quemado. La áspera trayectoria del Imperio Español en la trata de esclavos, el pánico de sus celosos inquisidores ante los seguidores de la reforma y su precaria condición de forastero, no le impidieron a The Spanish man agregar a su vocabulario las suficientes palabras inglesas para seducir a una mujer. El proceso que permite al semen fecundar un óvulo y transformarlo en feto cumplió normalmente su ciclo, en un silencio culpable, deshonroso. En el forcejeo de la criatura por nacer y la ira de una muerte segura envileciendo sus entrañas, la parturienta gritó ese ¡The Spanish man! colérico, pleno de odio contenido, que sonó a pañamán al apretujarse en la garganta enronquecida... The Spanish man...paña pañamán hijo de mala madre -en memoria de un hombre que fuera cazado como una comadreja y colgado para escarmiento de los huéspedes ingratos. (Buitrago 21-22)

Producida en el grito de muerte de la mujer a quien seduce el pañamán, el término capta culturalmente significados cambiantes en el contexto de la novela. ${ }^{5}$

4 Benítez Rojo apunta al hecho de que la leyenda "bien haya sido construida por la autora o recogida del folklore isleño, debe leerse como una zona insoslayable del libro...la llave para abrir la novela" (22).

5 Lingüísticamente, pañamán se deriva del contacto que existe entre el inglés estándar y el español estándar en la isla, traídos por los diferentes grupos que poblaron este espacio. Singulares cambios morfológicos y una afinidad fonológica producen una palabra compuesta producto de dos palabras diferentes: paña del español creolizado proveniente de la palabra España, y mán del inglés estándar man, hombre. En la palabra compuesta, paña es un préstamo proveniente de un sustantivo que sufre un cambio a nivel sintáctico y pasa a ser un adjetivo. Mán es un préstamo que mantiene el mismo significado y función gramatical de su lengua de origen, pero experimenta cambios a nivel morfológico al tomar un acento ortográfico de la lengua que lo asimila. Así, pañamán, Spanish man en inglés estándar, pasa a significar hombre español en el continuum lingüístico de San Gregorio, sin aludir solamente a la nacionalidad del mismo. 
El término pañamán "pronunciado despreciativamente por varias generaciones isleñas" (20) denomina, fundamentalmente, a toda persona del continente, advenedizo a la isla de clara descendencia española, o de cualquiera otra procedencia, como forma de "rechazo y desprecio contra el inmigrante colombiano -turco-judío-amarillo-piel blanca- de todas maneras extraño invasor" (21). Quiere decir un no-tinieblo, todo individuo que no exhibe en su piel el registro racial mezclado de los isleños. Pero un paña es también todo individuo mentiroso y deshonesto que se adhiere al decir isleño que indica la ingratitud de los que se aprovechan de la hospitalidad de los isleños donde los que lo desean pueden amasar buena fortuna. De ahí el dicho: "Paña, palomo y gato son animales ingratos". ${ }^{6}$ Los isleños resienten el poder que los pañamanes consiguen "[porque] desde que los pañamanes mandaban y comandaban en San Gregorio, la vida era realmente imposible. Estaban hartos de ellos. Sí. Cualquier día ocurriría lo mismo que en Belice o Nassau. ¡Le prenderían candela a todos los edificios de la civilización! Echarían a todos los pañas al infierno. Comerían gustosamente sus entrañas" (73). La cita enfatiza el carácter de invasor del Ser paña. La otra cara de los pañas, según Goyo Saldaña, los define como individuos advenedizos y desprovistos de un pasado identificable, porque pueden ser "muertos de hambre, sin la menor oportunidad de meter la mano en el caldero" (21). El acceso a las oportunidades disponibles en la isla de San Gregorio, consecuentemente, está lejos de ser definido únicamente por la condición de ser paña.

Ser paña puede ser, al mismo tiempo, un asunto de opción personal. Goyo Saldaña, por ejemplo, paña de nacimiento, "ignoraba que él no era ni blanco ni negro ni indio ni chino ni mulato, pero parecía tener una mezcla de todo ello. Su aspecto era exótico, aterrador" (22). A pesar del acceso que Saldaña tiene al ámbito paña de la isla-casinos, negocios, vida política a la que eventualmente se adhiere-, su vida transcurre en El Arenal, entre la barra de tinieblos y bajo los códigos isleños y deterministas.

Como parte de una leyenda, el pañamán es una figura arquetípica que condensa todas las subjetividades anteriores, además de portar el legado de los grupos colonizadores anteriores. La imposibilidad de definir su origen se materializa en su calidad de náufrago y en el hecho de que los restos del supuesto galeón nunca son referenciados. La inexistencia de una nave denota al pañamán como producto del Mar Caribe, llamado náufrago por haber salido del mar, punto de origen de todos los otros colonos y transeúntes que vienen a la isla. El Mar Caribe es el útero que engendra y le da vida a todos los grupos que habitan la isla en diferentes momentos de su historia: los ingleses puritanos, los franceses, los piratas, los indios Miskitos, los esclavos y cimarrones y, por último, los españoles y colombianos. Pero el hecho de que el pañamán provenga de la mátriz caribeña, el Mar

6 Este lema es la contraparte del lema continental, "Cachaco, palomo y gato son animales ingratos", el cual apunta a la tensión que existe entre los habitantes de la Costa norte de Colombia y los habitantes del interior del país. 
Caribe, de donde todo emana en el espacio caribeño, le brinda a la novela un carácter mágico. La magia, como sistema de pensamiento expresado en prácticas rituales y articulado en leyendas e historias como la leyenda del pañamán, performs a través de operaciones que "[postulate] an all-embracing determinism... [that] are divined and made use of in an all-embracing fashion" (Lévi Strauss 11).

De acuerdo al discurso antropológico, al que igualmente atañe Benítez Rojo, en las sociedades primigenias, lo mágico no se refiere a "a timid and stuttering form of science" (13). Por el contrario, el pensamiento mágico "forms a well-articulated system, and is in this respect independent of that other system which constitutes science" (13). La leyenda performs una operación mágica en tanto que relata cómo el agua salada del Mar Caribe vomita el pañamán, su aceptación por parte de la comunidad y sus acciones traicioneras son la causa de su muerte. Por esto, la leyenda articula una advertencia para todo forastero que penetre el espacio isleño y quebrante el orden del lugar. Como leyenda, ésta es una "historia" que "relate[s] a series of events that took place in a distant and fabulous past [...] [t]he actors in tales are heroes or miraculous animals, all the actors share the common trait that they do not belong to the everyday world $[. .$.$] the$ tales and fables refer to events that, even when they have caused changes in the World [...], have not altered the human condition as such" (Eliade 10-11).

El mitema ${ }^{7}$ de la leyenda se mueve entre la definición anterior y la coyuntura que surge de dos formas de narrar: la legitimada historia oficial y las historias que circulan y han circulado desde tiempos arcaicos dentro de la comunidad de la novela. El material producto de estas dos formas de percibir, registrar, contar y repetir da como resultado una leyenda que posee tanto un contenido profano, o sea relacionado con hechos "reales", como un contenido sagrado que relata lo que pasó realmente, "that really establishes the World and makes it what it is today" (Eliade 6).

La leyenda dice que, a la llegada del pañamán, éste se impuso por su apostura sobre los puritanos ya establecidos en la isla. Este hecho sitúa la leyenda en el siglo XVII, época en la que una colonia puritana inglesa ocupó la isla de Providencia. ${ }^{8}$ El orden

Utilizo aquí el término mitema para referirme al tema central de la leyenda. No lo utilizo de acuerdo a la definición de Lévi-Strauss.

8 En su libro San Andrés y Providencia: Una geografia histórica de las islas colombianas del Mar Caribe Occidental, James J. Parsons dice: "En Providencia los colonos se habían dispersado por la playa alrededor de la isla, formando varios centros habitados en la desembocadura de los arroyos que cruzan la isla con aguas permanentes. En una época había hasta tres pastores religiosos, cada uno con su propia iglesia parroquial. La población principal de Providencia estaba localizada en la costa noroeste sobre la Bahía Catalina, en el sitio que hoy se denomina Old Town. Se llamaba New Westminster, con un núcleo de 30 casas de madera, más una iglesia en ladrillo, y la casa del gobernador. Existe un buen récord de los gobernadores, con sus nombres, pero todo el vestigio de las estructuras de casas y demás edificaciones fueron borrados (sic); aún la propia existencia de una colonia puritana en la isla de Providencia hace más de tres siglos, es cosa desconocida a todos menos a un puñado de sus actuales habitantes" (25). 
social de la isla, dice la leyenda, se basa en la discriminación y segregación entre negros y blancos. El pañamán tuvo la necesidad de aprender algo de inglés para seducir a una mujer de la isla. Este elemento lingüístico pone en cuestión el origen de la mujer. La leyenda implica que el pañamán seduce a una de las colonas inglesas puritanas (Parsons 23). En efecto, de acuerdo a la organización social que la leyenda denuncia, la seducción de una esclava negra o de una mulata no constituiría una trasgresión bajo los códigos implícitos en una relación de poder que les permitía a los hombres blancos acceso a las esclavas. Sin embargo, a pesar de esta clara alusión al origen de la mujer a quien seduce el pañamán, la leyenda contiene su propio cuestionamiento. La separación entre blancos y negros ocurre, dice la leyenda, no obstante "la mayoría [posee] el color del tabaco quemado" (Buitrago 21). Este hecho afirma una mezcla racial ya existente entre las poblaciones segregadas de la isla y le brinda un tono diferente a la trasgresión del pañamán y la mujer "que habla inglés". La leyenda, en primera instancia, denuncia la injuria que el forastero impone sobre la comunidad al seducir a la colona. Los estrictos códigos puritanos requerirían la aprobación de la relación por parte de los líderes de la comunidad, la corte oficial y el matrimonio, además de reforzar la necesidad de contraer matrimonio con un miembro de su propio grupo social y étnico. Un examen más detallado del texto de la leyenda implica una denuncia de la mezcla obligada al referirse a la histórica penetración y violación sexual de mujeres "color del tabaco quemado", produciendo así "los tinieblos".

Sinónimo de penumbra y semi-oscuridad, ser tinieblo es pertenecer a una categoría que evade una definición precisa, tal como le explica Belinda a su patrona, Valentina Cisneros:

¡Ah, un tinieblo! Un tinieblo podía ser muchas cosas a la vez. Dijo [Belinda]. Eso era
la mismita cuestión de gustos. Ella no tenía parlamentos, modos de decirlo. ¿La señora
Valentina insistía? Un tinieblo era un tinieblo. Un tinieblo entra por la ventana y sale
a la madrugada por la puerta de atrás. Un tinieblo se saluda en el baile y se olvida en
la calle. Un tinieblo se quiere a oscuras y se desprecia en la claridad. A un tinieblo se
le fía y no se le cobra. Un tinieblo lo es y no lo es. (Buitrago, Los pañamanes 280)

En contraste con este ser y no ser del tinieblo, éste es, a su vez, el verdadero isleño, el habitante de El Arenal, la Zona Negra de la isla, foco de actividades legales e ilegales, y objeto de deseo de los pañas, quienes buscan controlar la economía de la isla.

Vale decir entonces que, dentro del universo de la novela, la leyenda del pañamán cumple la función de articular una explicación de la singular división social, racial y espacial que presenta la isla. El linchamiento del pañamán como "escarmiento de los huéspedes ingratos" (22) propone el rol del paña de chivo expiatorio, utilizado para restaurar un estado de cosas afectado por sus acciones a nivel inmediato y a nivel

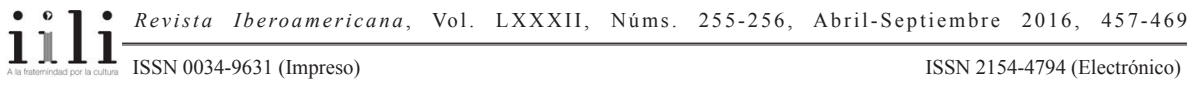


histórico. Es decir, según Benítez Rojo, para asegurar "la continuidad de la tradición racista en la isla" (228).

René Girard identifica diferentes usos de la expresión "chivo expiatorio". Entre aquéllos, el uso de dicha expresión en los siglos XIX y XX tiene mayor relevancia y aplicación a este estudio:

In the nineteenth and twentieth centuries, Frazer and others freely utilized the term scapegoat in connection with a large number of rituals. These rituals, they felt, were based on the belief that "guilt" or "sufferings" could be transferred from some community to a ritually designated victim, often an animal but sometimes a human being. (Girard, Violent Origins 73-74)

La leyenda es efectiva en su propósito al proveer una forma de transferir la culpa de varios grupos e individuos -los puritanos, los franceses, los holandeses- sobre el cuerpo de un ser de igual procedencia, quienes, como el pañamán, penetran la isla y la ocupan con planes provechosos sólo para ellos.

La muerte del pañamán reúne las características de un sacrificio por su naturaleza ritualista y colectiva, y por tener lugar en el espacio público. Al ser el linchamiento efectuado por los representantes de una colectividad quienes actúan de forma unánime, la muerte del pañamán puede ser vista como un rito de tipo chivo expiatorio, de acuerdo a los parámetros establecidos por René Girard. En el contexto de la novela, el rito cumple una función particular dentro de un ámbito moderno - utilizando modernidad y civilización como términos contiguos-. Es una muerte que desplaza la negación de la violencia que implica el acto de sacrificar al chivo expiatorio, ya que "[w]hether physical or psychological, the violence directed at the victim appears to be justified -justified by the responsibility of the scapegoat in bringing about some evil that must be avenged, something bad or harmful that must be resisted and suppressed" (Girard, Violent Origins 79).

Esta ecuación se complica al re-examinar la leyenda como un medio de repetición de un acto ya ejecutado anteriormente por otros, como el pañamán de piel blanca, provenientes del Mar Caribe: los colonos ingleses, los anteriores pobladores holandeses y franceses. En su calidad de intrusos en un espacio cuya historia oficial de descubrimiento y población es indefinida, la transgresión del pañamán ya ha ocurrido. Previos colonos habían traído a sus esclavos para trabajar en sus casas y en sus plantaciones de tabaco y coco y, al igual que la historia del resto del Caribe, ya habían impuesto su poderío sobre las esclavas a su disposición. El color de tabaco quemado que la mayoría de la población exhibe, según la leyenda, es testimonio de este cruce entre etnias.

Pero es interesante ver como la leyenda también proyecta una ambigüedad en cuanto a la participación de la mujer en su encuentro sexual con el pañamán. La unión y la fecundación ocurren en "un silencio culpable, deshonroso" (Buitrago 21), mientras los

111 11 Revista Iberoamericana, Vol. LXXXII, Núms. 255-256, Abril-Septiembre 2016, 457-469 
detalles del encuentro están definidos en términos de "seducción". 9 Esto deja abierta la posibilidad de aquiescencia entre los dos individuos, al tiempo que permite interpretar el encuentro entre los mismos como resultado de la astucia del pañamán y su "regia apostura" (21). A su vez, la astucia del pañamán apunta a una de las fuentes de la leyenda, las historias de la araña Kwaku Ananse de los Ashanti del oeste de África, elemento subrayado por Buitrago en la novela: "Kwake Ananse the Spider $^{10}$ is undoubtedly the best known rascal in West Africa. Shrewd and cunning, greedy and clever, his actions are those of a man, and he only returns to the cobwebs on the ceiling when he is in trouble and escaping punishment" (Arkhurst 9). Los héroes de estas historias son animales del bosque, como en el caso de Nancy, su nombre en español, y también pueden ser personas de la comunidad. Las historias encierran enseñanzas sobre las consecuencias de un acto transgresivo. De igual manera, las historias de Nancy demuestran la astucia como forma de existir, sobrevivir y de evadir un posible castigo.

Benítez Rojo apunta al uso de cuentos de Nancy por Buitrago, como elementos transculturados al folklore caribeño, ya "que el espíritu de las fábulas se ajustó a las condiciones propias del Caribe" (237). El texto de Buitrago confirma la inclusión de la tradición oral africana, ya apropiada en el Caribe, en el folio No. 75 que cierra el capítulo 6 de la novela. Luego del comentario del narrador sobre "la mente atiborrada de intrigas y vidas ajenas" (Buitrago 132) de Radamés Otero, sacerdote de la Zona Negra, el capítulo cierra con el contenido de "Una historia de Nancy," "FUENTE: TRADICIÓN ORAL (133). El título de la historia es "LA LEY QUE FORMÓ A NANCY”, encabezada por el proverbio "Cualquiera que se meta en las cosas ajenas tiene que morir" (133). Nancy vive con su ley hasta el día en que no puede resistir preguntarle a una gallina que pasa adónde va, y muere después de hacerle la pregunta. La relación entre los dos pasajes del texto se da alrededor del padre Otero quien viene a la Zona Negra con "la intención de aceptarlos [a los tinieblos] tal cual eran, ayudarles a tomar conciencia de sí mismos. Sin apiadarse de ellos o intentar reformarles a fuerza de sermones o acciones edificantes" (133), objetivo que no puede alcanzar. La ley de Nancy se cumple al recibir el padre

9 En Bahía Sonora, la colección de relatos de Fanny Buitrago, previa a Los pañamanes, la transcripción de Buitrago de la leyenda del pañamán se lee como a continuación en relación a la "seducción" de la mujer isleña y a su etnicidad: "En sus días de soledad y en sus noches de duermevela, sintiendo el zumbar de los mosquitos y presintiendo los reclamos de la luna, el hombre español soñaba con el cadencioso caminar de la muchacha más hermosa de la isla. Y aprendía suaves palabras inglesas, con el deseo de susurrarlas a su amor, para acompañar con ellas sus presentes de frutas y flores, realizados con todo el sigilo que su condición de forastero requería. La leyenda dice que el hombre español perdió a la muchacha. Lentamente su vientre liso comenzó a desfigurarse, el rostro moreno perdió suavidad y bajo sus enormes ojos, surgieron ojeras color aceituna. ¡El escándalo barrió las playas como huracán enfurecido...! ... Siempre los dientes cerrados, miedo o pesadilla, ocultando el nombre de aquel que había traicionado su amor" (158).

10 En Ghana, las historias de Anansi son llamadas anansesem -spider tales en Asante- Twi, el idioma de los Ashanti. 
Otero las consecuencias de su intervención en la Zona Negra. Dentro de la misma dinámica de trasgresión y punición, en la leyenda del pañamán, éste no puede escapar su castigo. Su muerte se convierte en la moraleja de la historia/novela.

Más allá de afirmar la relevancia de su estatus de código normativo, la novela define la tradición oral como materia que constituye la identidad del espacio y de sus habitantes. Es decir, lo oral es el producto textual de la realidad de San Gregorio. En todo momento, el acto de narrar las múltiples y rizomáticas historias que ocupan la novela es interrumpido-leáse impregnado-por las creencias, fábulas, apartes históricos y proverbios:

En hábil continuidad surgían sangrientas expediciones bucaneras, que se confundían con las figuras estoicas de los primeros colonos ingleses y holandeses, con sus virtuosas mujeres, sus fanáticos preceptos religiosos, su falta de escrúpulos comerciales y sus esclavos negros. Las terribles andanzas del Caballero de Jamaica. La leyenda del pañamán. De cómo el reverendo Nathan Henry atravesó todo el Caribe utilizando por nave una imponente iglesia de madera, pintada en un blanco inmaculado, y pudo llegar sano y salvo al viejo puerto de El Cove, a tiempo para predicar la doctrina salvadora de la Iglesia de Jesucristo de los Santos del Último Día. La epopeya de los remotos antepasados, quienes surcaron los mares bajo las banderas de España, Inglaterra y Portugal, destinados a reemplazar a las bestias de carga, cantores de funestas melodías en las bodegas de los barcos negreros. Y la estrategia desplegada por un puñado de tipos muertos de hambre - para defender las murallas de Cartagena- comandados por la mitad de otro tipo, alimentándose con espaldares de mecedoras y cueros de ratas, dignificados posteriormente en los anales de la patria. ¡Oh Patria, te adoro en mi silencio mudo y temo profanar tu nombre santo! iPor ti he sufrido y padecido tanto, como lengua mortal decir no pudo! (Buitrago 15)

La heterogeneidad del contenido de la dimensión oral de la novela es un espejo de la realidad del espacio de San Gregorio, -o sea San Andrés-a la vez que la heterogeneidad de San Gregorio reproduce la misma característica en la novela. Consecuentemente, el texto proyecta una imperiosa necesidad de "crear una leyenda. Una leyenda irrebatible, una leyenda concreta, una leyenda para esconder armoniosamente la verdad" (235). La leyenda es la novela misma en su afán de circular, por medio de la escritura, historias orales que expliquen, expandan, revelen y re-creen la realidad de San Gregorio.

La tensión que existe entre la oralidad y la escritura está ejemplificada en el texto a través del pánico ancestral de Pepe [el Tranquilo] por la palabra escrita (102). Para Pepe el Tranquilo, quien nunca ha salido de la isla, "no existía peor enemigo que la palabra escrita" (100). Cuando Pepe recibe una carta de manos de Sabina Galende aquélla es "como una acusación, como un maleficio, como un reto... La sola idea de la aleación tinta-papel bastaba para aterrorizarle mortalmente"(100). Pepe interpreta la escritura como la causa de la muerte de su protector, Campo Elías Saldaña, quien muere alcoholizado

111 11 Revista Iberoamericana, Vol. LXXXII, Núms. 255-256, Abril-Septiembre 2016, 457-469 
luego de perder su carrera política. Para Pepe, la muerte de Campo Elías ocurre "a causa del papel impreso y de la palabra escrita" (100). El miedo de Pepe es ratificado al encontrar Goyo Saldaña, quien se ofrece a leerla, que, efectivamente, la carta contiene una amenaza para El Arenal y para Nicasio Beltrán. Pero Goyo opta por no informarle a Pepe los malos augurios y le dice que es una cadena de la suerte de Fray Martín de Porras. Goyo guarda así el secreto del contenido de la carta, pero el miedo de Pepe lo hace seguir las instrucciones que él cree la carta contiene para evitar las consecuencias trágicas que pueden ocurrir al ignorar una cadena: "En la mañana compró siete sobres, y fue de casa en casa depositándolos por debajo de las puertas" (104).

El acto de Pepe el Tranquilo adjudica valores a la escritura que reconocen en ésta su poder de afectar la realidad de los personajes y la realidad de la isla. Sin embargo, la novela sólo puede preservar y privilegiar lo oral por medio de la escritura, sinónimo de modernidad, estabilidad, unilateralidad y autoridad. Para conseguir su objetivo, la novela se embarca en un proyecto que lucha por inscribir lo oral. Por consiguiente, el texto presenta una narrativa controlada por un narrador hetero e intra-diegético que no permite que el contenido se separe de su acto de contar. Por medio de la repetición de ciertos elementos como la creencia sobre los malos augurios que la muerte de un alcatraz produce y la inclusión de los documentos del archivo al final de cada capítulo, la novela adquiere un patrón rítmico. Este patrón guía al lector a través de una narrativa que existe en la escritura, pero que se enuncia desde lo oral, definido aquí en relación a los conceptos de oralidad desarrollados por Walter Ong. Así, el constante uso de proverbios y dichosformulas están inscritos en el texto para develar su capacidad normativa actual dentro de la realidad del espacio de la novela. Si se toma la novela como un todo oral, se puede observar cómo los capítulos funcionan de forma aditiva. Es decir, están subordinados el uno al otro de forma progresiva sin contener conclusiones propias. Walter Ong denomina el estilo que incluye porciones de discursos de suprema extensión un "additive oral style" (37), una característica que puede ser atribuida a la novela, especialmente en las citas que este estudio resalta en diferentes momentos. Los pañamanes cumple también con el principio oral que agrega los elementos y personajes de la narrativa sin esforzarse por analizar cada uno de ellos. La novela rebosa en abundancia y exceso de personajes, eventos y páginas, ya que se extiende a cuatrocientos quince folios. Tanto la voz narrativa como la unidad textual proyectan un deseo de conservar las historias que constituyen el espacio de la novela e inscribir "la historia no escrita" (Buitrago 305). El propósito es restaurar un equilibrio, el cual sólo existe en un momento que pertenece a una realidad anterior a la leyenda, creencia que circula, a su vez, dentro de lo oral. Las historias de la novela son producto directo o están basadas en eventos historiográficos los cuales son igualmente cuestionados por la tradición oral. Las constantes luchas entre grupos y entre individuos que la novela inscribe hacen referencia a una realidad impregnada de violencia que continúa sosteniéndose dentro de parámetros que subrayan

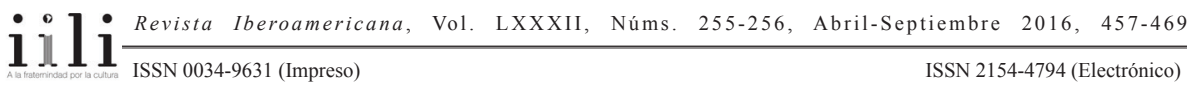


la violencia como común denominador y como factor inmutable. ${ }^{11}$ Es un "sistema de choque" (Benítez Rojo 238) que rescata la violencia como factor fundacional del Caribe, al tiempo que recurre al mito para desestabilizarla.

En los años sesenta, el tiempo de la novela, el espacio de San Gregorio y Fortuna es un Puerto Libre, exento de impuestos, al igual que San Andrés y Providencia. Su realidad no hace eco a las divisiones regionales del continente colombiano, ni a su supuesta dicotomía racial: la tri-etnia de la Costa Atlántica versus el criollismo de los habitantes del interior. Por tanto, el espacio isleño está constituido

por una multitud impaciente y vocinglera. Zarandeada a la deriva por llamativos automóviles de último modelo y ruidosas motocicletas corroídas por el salitre. Marinos de diversas nacionalidades, contrabandistas, pescadores, tostados aventureros, vendedores de drogas, mendigos y chanceros. Deambulaban altivos isleños de piel melada y luminosos ojos claros, atléticos suecos encandilados por el trópico, comerciantes activos y sudorosos, vagabundos de largos cabellos con las pupilas extraviadas, fanáticos propagandistas de la biblia y - de cuando en cuando- asustados turistas que perdieron a sus compañeros de excursión y las diversiones detalladas en los elegantes folletos de la Corporación Nacional de Turismo. Pregonan los yerbateros pomadas exóticas, raíces medicinales, collares de ajo, pulseras magnéticas y jarabes concentrados teñidos de violeta, mandarina y bermellón. En los tenderetes, cubiertos con planchas de zinc, se mueven con aire soñoliento los vendedores de fruta, como dopados por el furioso zumbido de las moscas. Se trafica con niñas, copra, ácido, divisas de importación, empleos públicos, carnes congeladas, materiales de construcción, artefactos eléctricos, perfumes y whisky adulterado. Están los adivinos. Las negras de uñas platinadas. Los narradores de cuentos. Los políticos incansables. Y todos los que ignorantes del pasado legendario de la isla emergen del cieno de su historia. Todos. Unidos por el lenguaje común de la gritería. En español, patois, inglés, árabe, ruso, yidish, italiano, hebreo, chino y portugués. (Buitrago 13; itálicas mías)

Existen en San Gregorio, en suma, elementos representativos de la realidad del espacio continental, del espacio insular caribeño y del sur de los Estados Unidos, "[t] odos. Unidos" (13). Su ya adjudicada condición de Puerto Libre y meca turística, aleja la isla del modelo de monopolio económico y del monocultivo, y le trae otras maldiciones a la población isleña. La novela, en gran parte por medio del uso del mito, recrea exitosamente la pluralidad del espacio caribeño colombiano, elementos que la cultura hegemónica continental, su discurso historiográfico y sus tendencias literarias no pueden recrear y plasmar con igual fidelidad. Benítez Rojo fue el primer crítico caribeño

11 En Orality and Literacy: The Technologizing of the Word, Walter Ong identifica las características del pensamiento y las expresiones basadas en lo oral. Creo que, como un todo que significa, Los pañamanes contiene el material necesario para llevar a cabo un estudio que identifique la afinidad que existe entre la novela y los principios que Ong define. 
en recuperar este valioso texto, ayudando así a corregir una falta en el Ser colombiano: el reconocimiento de su parte caribeña.

San Gregorio, como San Andrés, es un espacio de pluralidad donde ser paña es ser inglés, francés, holandés, africano, indígena, árabe y más recientemente "los aventureros del espacio (78), los “gringos,” denunciados en el grito “¡Go gome paña...!...Pañamán no good pañamán no good fuera pañamán get out of here" (81). Y ser "paña muerto de hambre" e "isleño de la mejor cepa" (139), como se define Nicasio Beltrán, es ser multilingüe y expresarse tanto en inglés estándar como en español estándar, al igual que desde numerosos momentos dentro de este continuo. Aún más, ser isleño es dominar también el irreverente costeñol de la costa norte de Colombia, virtud poseída por Terranova González alias El Manco, quien a pesar de las perennes clases de castellano siempre exhibe su habilidad lingüística: “¿Qué ha vidrios mis hermandades? ¿Cuál es la onda, dónde está el play, que si antes no nos vimos aquí estamos, a ponerse las pilas y mucho de folclor chévere y no me tiren escamas que este man la pasa full legal" (15). La inscripción de la poliglosia del espacio de San Gregorio es una prueba más de la agenda de la novela que consiste en afirmar la necesidad de continuar construyendo una mitología plurinacional tanto en el espacio colombiano como en el universo caribeño.

\section{BiBLIOGRAFÍA}

Aldana, Ligia S. "Violencia, raza, mito e historia en la literatura del Caribe colombiano". Tesis de doctorado. University of Miami, 2003.

Arkhurst, Joyce Cooper. The Adventures of Spider. Boston: Little Brown, 1964.

Benítez Rojo, Antonio. La isla que se repite: El Caribe y la perspectiva posmoderna. 2da. ed. Hanover, NH: Ediciones del Norte, 1996.

Buitrago, Fanny. Los pañamanes. Barcelona: Plaza \& Janés, 1979.

Bahía Sonora: Relatos de la isla. Vol. 15. Bogotá: Instituto Colombiano de Cultura, 1976.

Eliade, Mircea. Myth and Reality. Nueva York: Harper, 1963.

García Márquez, Gabriel. Cien años de soledad. Barcelona: Seix Barral, 1967.

Girard, René. "Generative Scapegoating." Violent Origins. Robert G. Hamerton-Kelly, ed. Stanford: Stanford UP, 1987. 73-105.

The Scapegoat. Yvonne Freccero, trad. Baltimore: John Hopkins UP, 1986.

Lévi Strauss, Claude. The Savage Mind. Chicago: Chicago UP, 1966.

Ong, Walter. Orality and Literacy: The Technologizing of the Word. Nueva York: Routledge, 1996.

Parsons, James J. San Andrés y Providencia: Una geografía histórica de las islas colombianas del Mar Caribe occidental. Bogotá: Banco de la República, 1964.

$111 \frac{\text { Revista Iberoamericana, Vol. LXXXII, Núms. 255-256, Abril-Septiembre 2016, 457-469 }}{\text { ISSN 0034-9631 (Impreso) }}$ 
